\title{
Linguistic Approaches to Ideology: Review of Work between 1979 and 2010
}

\author{
Gibreel Sadeq Alaghbary (Corresponding author) \\ Taiz University, Yemen \\ E-mail: gibreelsadeq@yahoo.om \\ Murad Alazzany \\ Sanaa University, Yemen \\ Ohood Al-Nakeeb \\ Independent Researcher
}

Received: 03-01-2015

Published: 01-09- 2015
Accepted: 05-03- 2015

doi:10.7575/aiac.ijalel.v.4n.5p.1
Advance Access Published: April 2015

URL: http://dx.doi.org/10.7575/aiac.ijalel.v.4n.5p.1

\begin{abstract}
The closing year of the 1970s saw the publication of two seminal books (Fowler, Hodge, Kress, \& Trew, 1979; Kress \& Hodge, 1979/1993) heralding a new direction in the investigation of textual ideologies. This methodology, called Critical Linguistics (henceforth CL), was language-oriented and drew its analytical apparatus from Halliday's Systemic Functional Grammar. Its aim was to "explore the value systems and sets of belief which reside in texts; to explore, in other words, ideology in language" (Simpson, 1993, p. 5 [original emphasis]). Ten years later, Fairclough (1989) took CL to a new plane where linguistic analysis became one of three levels of analysis, the other two focusing on interpreting language as a response to a particular social situation, and explaining this response in the constraining context of social and institutional structures. This approach was called Critical Discourse Analysis (henceforth CDA) and its linguistic component continued to be inspired by Halliday's model. The twenty years that followed produced a plethora of theories of CDA, divergent in their theoretical underpinnings but bound by a concern with investigating the reproduction of ideology in language. In 2010, Jeffries brought the linguistic component back to the forefront with the introduction of Critical Stylistics (henceforth CS). CS draws extensively, but not exclusively, on the linguistic components of CL and CDA. The present paper offers a critical survey of the three-decade developments (1971 through 2010) in the application of linguistic constructs and theories to the investigation of textual ideologies.
\end{abstract}

Keywords: Textual ideology, critical linguistics, critical discourse analysis, critical stylistics

\section{Introduction}

Though language is not the only means through which human beings interact in the world, it has become the main focus of discourse studies. This could be attributed to two reasons. The first is the function of language itself, which is perceived by practitioners in the field of language and representation to be purely ideological, or the center of the concept of ideology (Hall, 1982). Thus, practitioners in the field of discourse and representation emphasize that any attempt to recognize ideology will be aborted if language is neglected (Fairclough, 1992; Fowler, 1991; Hall, 1982; Trew, 1979; van Dijk, 1993). According to Hall (1982), language is the home of all ideology, and hence he gives it a crucial analytical role in identifying and analyzing ideologies. Hall's view has been embraced by Traynor (2004), who emphasizes the influential and analytical role of language in representational discourse. He describes language as:

[t]he most significant and colossal work that the human spirit has evolved, it maintains itself as the source of all arts and the core of all science. It is always known as the most massive and inclusive art we know, a mountainous and anonymous work of unconscious generations. (Traynor, 2004, p. 1)

This concurs with Chilton's view (2004) that sees language as the most effective and most developed medium human beings use to interact and communicate with each other. He states that human beings use language not only to communicate with each other but also to represent the world the way they want.

The second reason is the nature of language. Recognized as a system of representation in ordinary practice and use, it does not present real life but it re-represents it (Scannell, 1998). In this perspective, language is not seen as abstract grammatical categories as it is viewed within traditional linguistics (van Dijk, 2002). Instead, it is viewed as a medium that is impregnated with ideology. Similarly, Bell and Garrett (1998) see language as a medium of instruction that cannot be used in a vacuum. It is part of a context in which social relations go hand in hand with language use. In this regard, language is viewed as a political tool with a potential to convey messages, depict images and mediate concepts to reflect and influence the formation and expression of culture, politics and social life. 
Since there is no doubt about the function of language in representing the world in terms of concepts and ideas, language is given a fundamental role in discourse studies. It is dealt with as a communicative tool, which is saturated with ideological patterns, concepts and values (Fowler, 1991; Simpson, 1993). Many approaches, like CL, conversation analysis, CDA, feminist stylistics and critical stylistics have been developed by researchers to unravel the ideologies conveyed by language, or silently presupposed in the texture of different text types.

\section{Ideology}

Language is a socially purposive action. According to Fairclough and Wodak (1997), language is a social practice; it serves to represent things, position people, and therefore organize social life. As such, it has become the site for competing discourses, with consequences for ideology.

The term 'ideology' was first introduced by the French philosopher Destutt de Tracy in the eighteenth century and since then it has, in fact, attracted the attention of scholars from different disciplines such as cognitive and social psychology, sociology and discourse analysis, resulting in a whole range of definitions varying in focus but underscored by similar concerns. For example, social sciences like sociology, political science, socio-psychology and linguistics are all concerned with ideology but from different perspectives. The first three neglect the function of language in constructing and mediating ideology - a concern that has recently been embraced by discourse-oriented linguistics (Wodak, 1989).

Although Eagleton (1991) declares that "nobody has yet come up with a single adequate definition of ideology" (p. 1), he lists sixteen different definitions for the term that existed at his time, most of which are related to social dominance and political power. Eagleton criticizes those accounts for being either pejorative, ambiguous, neutral or inadequate. Through his progressive criticisms, Eagleton reaches out to explain ideology in six different ways.

First, Eagleton (1991) generally defines ideology as synchronized with culture as "the general material process of production of ideas, beliefs and values in social life" (p. 28). He, also, defines it less generally as "ideas and beliefs (whether true or false) which symbolize the conditions and life experiences of a specific, socially significant group or class" (p. 28). That is, ideology is a representation of social practices and experiences.

Moreover, ideology is a "discursive field in which self-promoting social powers conflict and collide over questions central to the reproduction of social power as a whole" (Eagleton, 1991, p. 29). The fourth definition emphasizes the dominance of social power, and assumes that "dominant ideologies help to unify a social formation in ways convenient for its rulers; that it is not simply a matter of imposing ideas from above but of securing the complicity of subordinated classes and groups, and so on" (p. 30 [original emphasis]).

In his fifth definition, Eagleton (1991) restricts the notion of ideology to signify a specific dominant group or class. He states, "ideology signifies ideas and beliefs which help to legitimate the interests of a ruling group or class specifically by distortion and dissimulation" (p. 30). In his last account of the term, Eagleton argues that ideology "retains an emphasis on false or deceptive beliefs" (p. 30), however, these beliefs are not the production of a controlling class, rather, they are formed in accordance with the whole society.

Although Eagleton (1991) has extensively tried to define ideology, his definitions have failed to wipe out the vagueness of the term. In fact, since the publication of Eagleton's Ideology: An Introduction in 1991, the term has attracted scholars' attention leading them to have 'ideology' on the covers of their books (e.g., Cormak 1992; Hawkes, 1996; Huck \& Goldsmith 1995; Schieffelin et al.,1998; Simpson 1993; van Dijk, 1998a).

Scholars, who are concerned with the term as related to discourse, (e.g., Fairclough, 2003; Simpson, 1993, 2004; van Dijk, 1998a), have attempted their own descriptions of the term. According to Fairclough (2003),

Ideologies are representations of aspects of the world which contribute to establishing and maintaining relations of power, domination and exploitation. They may be enacted in ways of interaction (and therefore in genres) and inculcated in ways of being identities (and therefore styles). Analysis of texts ... is an important aspect of ideological analysis and critique. (p. 28)

Simpson (2004) defines it as "the matrix of beliefs we use to comprehend the world and to the value systems through and by which we interact in society" (p. 78). Van Dijk (1998a) provides a multidisciplinary definition; that is, ideology is defined in association with three overlapping disciplines: cognition, society and discourse. That is to say that, ideology, as a set of ideas that are mentally processed and socially practiced by a group of people or a specific class, is communicated through language use.

What all of the previous multifaceted definitions have in common is that they discuss the notion of ideology as beliefs. Ideology, therefore, may be defined as the set of ideas or beliefs, "any set of beliefs" (Eagleton, 1991, p. 2 [original emphasis]) that is shared by a particular community and that affects their outlook on the world. In other words, it is a normative vision, a way of conceptualizing the world.

The term 'ideology' has different connotations in different registers. In critical investigations of language use, the term is generally used not in a positivistic sense. It is used to refer to the insidious, manipulative beliefs that are often disguised in apparently disinterested language use. It becomes the job of the analyst to unmask these ideologies and foreground the naturalization of dominant ideologies. The investigation of ideological control in texts was initiated in the 1970s by a group of linguists at the University of East Anglia. The concern with power structures in language continued through the $1980 \mathrm{~s}$ and is well and alive in critical circles today. 


\section{Critical Linguistics and Ideology}

Fowler and Kress (1979) contribute the last chapter of Language and Control (1979) entitled Critical Linguistics, which has marked a turning point in the study of the interplay of language and ideology. The authors argue that there is a definite need for an approach to the study of ideology in texts. Fowler and Kress suggest that this approach be linguistic and critical. They argue that linguistic analysis is 'a powerful tool' in the study of ideology, and the mediation of power and control in texts. The approach is also critical because the analysis is not a mere description of the linguistic features of texts, but rather an interpretation of the text and the underlying ideologies that lie beneath the linguistic form.

To realize this objective, CL adopts the descriptive apparatus of Systemic Functional Grammar (Halliday 1978, 1985), which was introduced around the same time and which shared the view of language as created and embedded in social context. CL posits that language reproduces dominant ideologies which in turn maintain asymmetrical power relations, and sets out to "demonstrate that grammatical and semantic forms can be used as ideological instruments to make meaning in texts and classify things, people and events" (Simpson \& Mayr, 2010, p. 50).

Fowler and Kress' (1979) contribution is based on their criticisms of the linguistics of their time. They are critical of the structuralist school of linguistics, which claims that meaning and style are separable. CL differs from structural and Chomskyan schools of linguistics in the sense that it strongly links linguistic forms to the society in which they are employed. (Fowler \& Kress, 1979). According to Fowler and Kress, "lexical items, linguistic forms and linguistic processes carry specific meanings" (p. 186). Furthermore, they challenge the Chomskyan view that language is not social in nature, and that language structure is dissociated of language use. Fowler and Kress criticize this school of linguistics, and argue that people's "total language ability is a product of social structure" (p. 187). According to CL, "[l]anguage serves to confirm and consolidate the organizations which shape it, being used to manipulate people, to establish and maintain them in economically convenient roles and statuses, to maintain the power of state agencies, corporations and other institutions" (p. 190).

$\mathrm{CL}$ is "an approach to language study which uses linguistic techniques to investigate the ideologies (value-systems and sets of beliefs) which underlie texts" (Carter \& Simpson, 1989, p. 91). From a critical linguistic point of view, language facilitates, confirms, constructs, mediates, produces and reproduces ideology (Birch, 1989; Fowler \& Kress, 1979; Simpson, 1993). This construction, mediation, production or reproduction mainly depends on 'social' structures. That is, according to Fowler and Kress (1979) linguistic structure and social structure are strongly connected in the sense that social groupings and relationships, institutions and the socioeconomic systems have an impact on the speakers' and writers' cognitive and linguistic behavior. Texts are the productions of these structures, and the social and interpretative meanings of texts are definitely influenced by the linguistic structure of texts and the socio-economic system. In fact, any text entails ideology and an evaluation of a specific matter (Fowler \& Kress, 1979). Fowler and Kress provide a checklist that can be applied to the analysis of any texts. The checklist is offered under five headings: the grammar of transitivity, the grammar of modality, transformations, classification and coherence, and order and unity.

Along with the publication of Language and Control, Kress and Hodge (1979/1993) contribute to the field of CL their collaborated work Language as Ideology. Similar to Fowler and Kress (1979) Kress and Hodge (1979/1993) take their toolkit from Halliday's functional approach. Furthermore, they aim to produce a new kind of linguistics that is "socially responsive" and "to produce a linguistics with social effects, through revealing the structures of power in language use" (as cited in Lindstrand, 2008, p. 61). That is, a linguistics that is critical in nature. Kress and Hodge (1979/1993) are concerned with the problem of power presentation in texts arguing that ideology is "a systematically organized presentation of reality" (p. 15). They are interested in how linguistic features such as nominalization, passivization, transformation, etc. produce the ideological effects of texts.

Kress and Hodge (1988) take the critical analysis of ideology beyond language. In fact, Hodge and Kress carry the notion of ideology and the power presentation presented in texts to the study of signs and to the consideration of the linguistic choices made by a speaker or a writer as an act of sign. According to Hodge and Kress, signs are expressions of our "disposition, habitus, identity" (as cited in Lindstrand, 2008, p. 62). Although ideology is still the concern of Hodge and Kress' new development of CL, language is not given primacy in the critical linguistic analysis because there is a shift into signs, photographs, sculptures, children's drawings, etc. - that is, interest has shifted to social semiotics (Lindstrand, 2008). For Hodge and Kress, meaning is not only encoded through language, rather, it resides in other systems such as paintings.

The critical analysis of visuals has also seized the attention of Mills (1995) whose work Feminist Stylistics has marked a starting point in the analysis of ideology from a feministic point of view. Similar to Fowler and Kress's (1979) critical linguistic analysis, a feminist stylistic analysis concentrates on the linguistics of texts in order to unmask hidden ideologies. However, Mills (1995) shares Hodge and Kress's (1988) interest in advancing the analysis of ideologies interwoven in texts to the analysis of ideology transmitted through visuals. Mills argues, "this at least does try to present texts within their context and in their entirety" (p. 10). Mills concerns both types of communication systems, verbal and visual, and attempts to provide a toolkit that can be applied to the analysis of verbal meaning encoded through linguistic structure, and to the analysis of images. This toolkit, like other linguistic toolkits, depends mainly on Halliday's systematic functional school of linguistics.

There are two important objectives that set feminist stylistics apart from the kind of CL introduced by Fowler and Kress (1979), and Hodge and Kress (1988). First, it is mainly concerned with underpinning ideologies as related to gender. It concerns 'gender differences'; that is, the representation of men or women in texts, words and images. Mill (1995) 
argues that feminist stylistics aims to "contest", "reinterpret", or even "make strange" how men and women are portrayed in order to find other ways of representing genders "differently and more productively" (p. 2). Second, Mills claims that her approach, unlike the previous critical linguistic approaches to ideology, calls for 'change'. Mills states that feminist stylistics aims to "draw attention to and change the way that gender is represented" (p. 1).

Another contribution to the field is Fowler's Language in the News: Discourse and Ideology in the Press, published in 1991. Like Mills (1995), Fowler (1991) studies gender in discourse, and he identifies a variety of discursive strategies that seem to aid the consolidation of ideologies such as that of discrimination. For example, in addition to the strategy of selection, he finds that the discourse of women is itself used as a strategy to promote men to be more professional than women in their careers. At the same time, Fowler identifies a number of discursive strategies for the intensification of press hysteria in the coverage of health crises in some English newspapers like the Guardian, the Independent and Sunday Times. These discursive strategies include vocabulary emphasizing negative emotions (such as fear and confusion), risk and danger, and using unfamiliar, and therefore alienating, technical and medical jargon, the 'rhetoric of animation' applied especially to 'bugs', melodramatic and metaphoric language which refers intertextually to horror and science fiction films, and the 'rhetoric of quantification'. The 'rhetoric quantification' as a discursive strategy is especially applied in providing numeral expressions that indicate large quantities or count numbers of different entities (food poisoning, Salmonella poisoning, and Salmonella enteritidis poisoning) (Fowler, 1991). Such represented quantities and numbers are designated by some dramatic verbs and nouns like 'increase', 'rise, 'amount', 'spread', jump', 'proliferation' and 'escalation' (Fowler, 1991). Through these expressions and the statistical tags that accompany them, the quantities inevitably blur; they actually become more like impressions rather than facts. Thus, with such a strategy, the discourse becomes constantly alarming, hyperbolic and, hence, hysteric (Fowler, 1991, pp. 164-9).

Following Fowler (1991), Kuo (2003) explores the quotation patterns in two ideologically opposed newspapers in Taiwan, namely the pro-unification United Daily News, and the pro-independence Liberty Times. He finds that in reporting the Taiwan President Chen Shui-bian's 'one country on each side' statement, the two newspapers differ significantly in their selection of quotation contents and quoted speakers. The same speaker is quoted as saying completely different things by the two newspapers, which are also more likely to quote those who voice their positions on controversial political issues. As a result, Kuo's study has demonstrated that the choice of quotation patterns is by no means objective or neutral, and presentations of speech in the news tend to contain some degree of intervention of mediation.

What Mills (1995) and Fowler (1991) have in common is their focus on the investigation of power presentation, with a special emphasis on social 'discrimination', in texts, and what sets them apart is the angle from which they approach textual language. Mills argues that her central interest in analyzing texts and images is to unfold ideological perspectives on 'gender', and Fowler, although concerned with 'gender', extends the territory of CL by using a variety of discursive strategies to investigate (news) discourse. Their contributions do not only differ from the CL that appeared in 1979 and 1988, but they are also at a variance of Fairclough's (1989) CDA. The latter is a broadened version of CL that appeared in 1989 bringing back the study of the ideological embodiments of language in wider contexts including history, culture and socio-cognition.

\subsection{Critical Discourse Analysis: A Development of Critical Linguistics}

CDA also has its roots in CL, which was initiated or developed by the group of linguists and literary theorists at the University of East Anglia in the late 1970s (Fowler et. al., 1979; Kress \& Hodge, 1979/1993) to study the ideologies that are embedded in linguistic structures. The new approach was laid out in Fairclough (1989) Language and Power, and adopts the methodological principles of CL. CDA broadens these concerns to include contextual factors such as historical, cultural and sociocognitive considerations (van Dijk, 1995; Wodak \& Chilton, 2005).

Much has been written about CDA in the last two decades. Van Dijk (1997) and Fairclough (1995) provide us with useful definitions that encapsulate most other definitions of CDA. CDA has been recognized by van Dijk (1997) as a field that is concerned with studying and analyzing written and spoken texts to reveal the discursive sources of power, dominance, inequality and bias. From van Dijk's perspective, CDA examines how these discursive sources are maintained and reproduced within specific social, political and historical contexts.

In a similar vein, Fairclough (1995) defines CDA as discourse analysis, which aims to systematically explore often opaque relationships of causality and determination between (a) discursive practices, events and texts, and (b) wider social and cultural structures, relations and processes. Such an approach does not view discourse analysis to be merely a linguistic analysis of texts. In fact, Fairclough (2003) views it as an approach that oscillates between a focus on specific texts and a focus on what he calls order of discourse, the relatively durable social structuring of language, which is itself one element of the relatively durable structuring and networking of social practices. That is due to the fact that Fairclough's approach to CDA is based upon the assumption that language is an irreducible part of social life, dialectically interconnected with other elements of social life, so that it CDA always has to take account of language.

Fairclough (2003) introduces this approach as one productive way of doing social research through a focus on language and through using some forms of discourse analysis. In this sense, it would be worth noting that Fairclough does not view his approach of CDA as a matter of reducing social life to language, saying that everything is discourse. Rather, his approach appears as one analytical strategy amongst many, and according to him, it often makes sense to use discourse analysis in conjunction with other forms of analysis, for instance ethnography or other forms of institutional analysis. He emphasizes that $\mathrm{CDA}$ is concerned with continuity and change at this more abstract and more structural 
level, as well as with what happens in particular texts. Thus, Fairclough's approach investigates how such practices, events and texts are ideologically shaped by relations of power and struggle over power, and explores how the opacity of these relationships between discourse and society secures power and hegemony.

The above views of CDA belong to two persons (van Dijk and Fairclough) whose contribution to the field is viewed to be the most comprehensive work on discourse studies to date, and they have continued to extend the range of their work to many themes such as racism, globalization, and capitalism issues that have an influential echo in the area (Bell \& Garrett, 1998). However, there are many other definitions that are still available on CDA. The availability of these definitions rises from the fact that many practitioners look at CDA from different angles and define it from different perspectives depending on the themes they aim to address. The availability of these definitions of CDA make it a multidisciplinary approach "whose overall aim has been to link linguistic analysis to social and ideological analysis" (Richardson, 2004, p. 6). This is to say that, CDA becomes a visible and applicable approach that enjoys a hegemonic position in media studies (Bell \& Garrett, 1998).

The hegemonic position, according to Teo (2000), maintained as CDA, is found to be applicable in many representational studies that have different data, different scopes, and aims, or as Richardson (2004) puts it,

CDA sees itself as politically involved research with emancipatory requirements: it seeks to have an effect on social practice and social relationships' particular relationships of disempowerment, dominance, prejudice and/or discrimination. (p. 7)

This feature of applicability and the hegemonic position of CDA in discourse studies have been acknowledged by many researchers in many volumes. Bell and Garrett (1998) have reported that CDA has formed the basis of analysis for the majority of research into media discourse during the 1980s and 1990s, and arguably, it has become the standard framework for studying media texts within European linguistics and discourse.

However, the question that is posed is what makes CDA applicable and hegemonic. There is literature that sees the applicability of CDA and its hegemonic position in media studies to be maintained due to the centrality of ideology in its methodological approaches (Fairclough, 1989; Fowler, 1991; Scannell, 1998; van Dijk, 1993). As an analytical tool, CDA challenges us to move away from seeing language as abstract to seeing our words as having meaning in a particular historical, social, and political situation (McGregor, 2003). McGregor (2003) points out that CDA views our words (written or oral) never to be neutral but rather perceived as carriers of a broad sense of meaning and the meaning they convey is identified by its immediate social, political, and historical conditions. Therefore, it is assumed that news, while representing events, endorses values and meanings embedded in the choices of linguistic structures, just as Fowler (1991) claims that "anything said or written about the world is articulated from a particular ideological position" (p. 10).

From another perspective, the applicability of CDA draws its strength from its advantage of being a multi-disciplinary and multi-dimensional approach in a way that can serve studies like those that address themes like racism, sexism, social equality and other representational themes.

O'dartey-Wellington (2004) understands the multi-disciplinarity of CDA to be due to the roots that CDA has in the fields that give the concept of ideology a particular inflection in their contemporary popular culture studies. Though they admit that CDA is relatively a young discipline, they trace its roots to Marx, whose ideas on social theory and organization have had a tremendous impact on latter-day social thinkers. They even assert that CDA, as a current and accumulative theoretical approach, culminates the work of many scholars like Althusser (1971), Gramsci (1971), and Habermas (1984). For instance, they demonstrate that Gramsci and Althusser have both stressed the significance of ideology for modern societies to sustain and reinforce their social structures and relations, while Habermas focuses upon the 'colonization' of the 'life-world' by the 'system' of the 'economy and the state'. Neo-Marxist in orientation, these views on social theory converge on the role of an abstract system of socio-political ideology in the construction and indeed reproduction of modern-day society. As a pre-eminent manifestation of this socially constitutive ideology, language becomes the primary instrument through which ideology is transmitted, enacted and reproduced (Foucault, 1978; Pecheux, 1982). Thus, by analyzing linguistic structures and discursive strategies in the light of their interactional and wider social contexts, we can unlock the ideologies and recover the social meanings expressed in discourse.

The social theories of Foucault (1978), Habermas (1984) and others have in turn influenced, albeit to varying degrees, the work of linguists like Fowler et al. (1979) and, more recently, Fairclough (1995), van Dijk (1998b) and Wodak (2002), who share a common vision of the centrality of language as a means of social construction. Working independently but united by this common vision, they embark upon various investigatory studies designed to unmask and make transparent the kind of socio-political or socio-cultural ideologies that have become entrenched and naturalized overtime in discourse.

In summary, CDA and CL share the theoretical concern of investigating ideological structures in texts and a methodological interest in language but differ in the rigor of the linguistic methodology and the multi-discplinarity of theoretical underpinnings.

\section{Critical Discourse Analysis and Ideology}

In recent decades, the question of ideology has been the central theme in analytical discourse studies. For instance, Scannell (1998) views the overall concern and focus of analytical discourse studies to be ideological. At the same time, he emphasizes that the concept of ideology stands like a colossus over the field of discourse studies. In a similar way, 
Hall (1982) emphasizes that the primary function of language is ideological. He points out that since language is both a system of communication and representation, in ordinary practice and use, it is necessary for the concept of ideology to be central to the critical analytical studies. In the same vein, Richardson (1998) states that most discourse approaches are commonly used with the question of representation in discourse and often with the object of determining the ideological character of representation.

Due to the centrality of ideology in language, many analytical approaches are designed to address that concept (Richardson, 1998). The main discursive approaches that are devised to address the question of ideology in discourse are the CL and CDA approaches which are proposed by linguists, such as notably Fairclough, Fowler, Kress, Trew, van Dijk, Wodak, and many other analytical discourse practitioners (Scannell, 1998). These analytical approaches become the standard framework for studying texts in linguistics and discourse studies. They are consistently used to analyze discourses and to reveal the hidden ideologies that are used to represent groups. Within these approaches, media pioneers emphasize that ideologies reside in text and hence dictate their work to examine how these hidden ideologies are maintained, and reproduced within specific social and historical contexts (van Dijk, 1998a).

Social and discourse studies often begin with remarks about the vagueness of the notion of ideology due to its elusive definition and the resulting theoretical confusion of its analysis (van Dijk, 1998a). However, it must be emphasized that whatever else ideologies are, they have always been associated with socially shared ideas. Their basic sense means that they are simply a system of ideas, themes, values, attitudes and categories that are used as a reference to comprehend and interpret the world in terms of social and political representations (van Dijk, 1998a). In critical discourse studies, particularly those which take a political trajectory, ideologies are understood in two ways: as a natural term they refer to any articulate system of values and themes (Catholicism, Marxism, Thatcherism etc.) and as a critical term, they refer to distorted value systems or beliefs which in reality work against the interests of the majority (Scannell, 1998). Within the CDA approach, Fairclough (2003) views ideologies as representations of aspects of the world, which can be shown to contribute to establishing, maintaining and changing social relations of power, domination and exploitation. This definition shows that Fairclough views ideology as a modality of power, in contrast with the various descriptive approaches that view ideology as positions, attitudes, beliefs, perspectives, and so forth of social groups without reference to relations of power and domination between such groups. In this respect, Fairclough (2008) points out that ideological representation can be identified in texts as meaning in the service of power. Therefore, a particular ideological representation of some realities might appear as merely a transparent reflection of some reality. Thus, for Fairclough, ideologies are judged in terms of their social effects, rather than in terms of their truth values.

In this sense, the aim of ideology critique is to reveal how ideologies render themselves invisible to be consolidated in certain themes and realities and in such ways that make them escape notice. This is to understand, for instance, how a racist ideology render themes like immigration, a feminist ideology render themes like abortion or gender inequality in society and how a social ideology may render themes that concern public affairs (Scannell, 1998).

From a cognitive perspective, van Dijk (1998) recognizes ideologies as social representations since they are used to define the social identity of a group of members and their shared beliefs. He also considers ideologies and opinions of text procedures in the newspaper not to be impersonal but rather social, institutional or political. These two views have been integrated by van Dijk in a socio-cognitive theory that deals with shared social representations and their acquisition and uses in social contexts. Based on this theory, van Dijk provides a comprehensive view of the interactive relationships among discourse, ideology, and media which is represented by an analysis of the 'triangle' of cognition, society, and discourse. In this triangle, van Dijk (1998b) defines ideologies from a social cognitive perspective as 'interpretation frameworks' that organize sets of attitudes about certain elements and issues in a society. These attitudes may be used in the formation of personal opinions as expressed in mental models. According to van Dijk, these mental models control how people act, speak, write or how they understand the social practices of others. In addition, he states that these mental representations are often articulated in terms of prepositions that demonstrate themes such $U s$ versus Them. Within such a theme, the speakers of one group tend generally to present themselves or their own group in positive terms while they represent the other group in negative terms (van Dijk, 1998b). Analyzing and making explicit this contrastive dimension of $U_{s}$ versus Them has been central to most of van Dijk's research and writings.

From a cognitive perspective, van Dijk (1993) focuses on the discursive strategies that uncover power struggle, social inequality and any other form of social and political problems. In another study on racism, van Dijk (2006) focuses on the discursive strategies used by the elite to enact, sustain, legitimate and reproduce social, particularly racial, inequality in the media as well as other public domains. The discursive strategies that are found by van Dijk to be dominant in the racism discourse are the denial, naturalization and justification strategies. He demonstrates that such strategies are usually utilized when interviewees speak or act in a way to distance themselves from being racist and in a way to blame the victims for their circumstances regarding their own social, economic and even cultural disadvantages. In addition, he finds the justification strategy, which is used in the inequality or racism discourses of ethnic minorities, to involve two complementary strategies, namely the positive representation strategies of a group, and the negative representation strategies for the others. Van Dijk states that both of these strategies are used to create a clear distinction between the superior 'self' and the inferior 'other'. For instance, positive representation strategies are persuasively used to convey self-glorification, which he finds to be routine in either criticizing or denying responsibility with regard to acts of racism. In contrast, the negative other-representation strategies are used to make derogatory remarks about others by referring either to their lack of discipline or to other acts that may be viewed as negative. This is to say that the justification strategy is usually utilized in the racism discourse to emphasize our tolerance and to highlight the negative 
social or cultural differences of others and the deviance or threats attributed to them. Van Dijk (2006) demonstrates that if polarized representation strategies of the others are consistently used with negative attitudes, they may sustain existing attitudes and then form new negative ideologies and perceptions of the others. For instance, he points out that the vicious circle of the limited employment opportunities, poverty and consequent assimilation into a culture of drugs and crime among African Americans could be rationalized by such strategies when they are used in the racist discourse of the majority versus minority (van Dijk, 2006, p. 375).

Using van Dijk's (2006) socio-cognitive approach to critical discourse analysis, Alazzany (2014) analyzes the political goals and themes in the speeches of Yemen's former president, Ali Abdullah Saleh'. Alazzany finds that Saleh uses socially resonant themes such as patriotism, legitimacy, and democracy in an attempt to influence public attitudes. Among the discursive strategies which are found to be used by Saleh dominantly is representing the protests as a threat to the country's stability and security, and as illegitimate acts that contradicted the principles and values of democracy, while portraying himself as an elected, legitimate president in a country ruled by democratic institutions. The study finds analytically that Saleh's speeches also employed specific discursive strategies including classification, speech acts, and charges of conspiracy.

Still within the CDA approach, Fairclough (2003) views texts to be inevitably and unavoidably ideological in a sense that "any utterance is a link in a very complexly organized chain of other utterances" with which "it enters into one kind of relation or another" (p. 42). However, he shows that texts differ in their orientation, theorizing that the relation of an utterance to others may be a matter of building on them, polemicizing with them. This is because meanings are produced through interpretation of texts and texts are open to different interpretations depending on the context in which they exist. In addition, ideological processes pertain to discourse as whole social events that reflect different contexts.

On the other hand, Fairclough (2003) notes that for any particular text or type of text, there is a set of other texts and a set of voices which are potentially relevant, and potentially incorporated into the text. However, he demonstrates that it may not be possible to identify these sets with great precision as they are rather extensive and complex. Thus, Fairclough commits himself to the theoretical claim that texts have intertextual relations and inevitably make assumptions which are significant for the ideological analysis of texts. Therefore, he identifies the ideological work of any text to be partly a matter of intertextuality, which focuses on how the context is brought into the text, and explains how texts draw upon, incorporate, recontextualize and dialogue with other texts. He also identifies intertextuality to be partly a matter of assumptions which are implicit meanings of texts in a sense that what is said in a text is always said against the background of what is unsaid - what is made explicit is always grounded in what is left implicit. Fairclough highlights an important contrast between intertextuality and assumption in a way that intertextuality broadly focuses on what is included and what is excluded from the events and texts are represented by bringing other voices into a text. Assumptions, on the other hand, broadly reduce differences by assuming common ground. However, Fairclough (2003) emphasizes that, ideologies, whether they are assumptions, a property of events or a property of structures, must be handled in terms of thematization.

\section{Critical Stylistics: A Recent Development}

The approach named CS emerged in 2010 with the publication of Jeffries' Critical Stylistics: The Power of English. Like other trends in stylistics, CS uses insights and findings from formal linguistics as a basis for the interpretation of texts. What sets it apart from mainstream stylistics, however, is an extension of concern beyond description and an expansion of horizon beyond literature. Critical stylisticians do not analyze the linguistic make-up of texts for the sake of analysis and do not aim at hypothesizing interpretive claims of texts; they use "the linguistic features that are already well-described in very many semantico-grammatical theories and models" as a means for the analysis of "the different ways in which texts allow/ask us to conceptualize those topics they are addressing, and to provide some means of accessing this representational practice" (Jeffries, 2010, p. 14). They expose insidious language use and the way ideologies are "communicated, reproduced, constructed and negotiated using language" (Jeffries, 2010a, p. 5), and the sites for this investigation include media, legal, political, and corporate texts, while taking on board the traditional concern with literature.

The concern with ideology and the heterogeneity of text types analyzed are a continuation of the tradition started by CL and extended by critical discourse analysts. CS, however, revives the CL heritage of giving primacy to the text in the investigation of ideology (Jeffries, 2010). In consistence with this outlook, the proposed approach is named critical stylistics. CS is an attempt to "combine the text analysis of stylistics with the ideological awareness of CDA" (Jeffries \& McIntyre, 2010, p. 194).

The approach is not a complete departure from the critical practice of CDA and its forerunner CL; in fact, it is an extension of the tradition to scrutinize "the precise ways in which texts may transmit, reinforce or inculcate ideologies in their readers" (Jeffries, 2010, p. 12). Jeffries aligns her approach more with CL than with CDA, though. She agrees with Simpson (1993) that "a particular style represents certain selections from a pool of available options in the linguistic system" and that these selections privilege "certain readings, certain ways of seeing things, while suppressing or downplaying others" and the so analyst's job is to "decode the stylistic choices which shape a text's meaning" (p. 8). By contrast, CDA analysts are more interested in "explaining how texts fit into the socio-political landscape in which they are produced and read" (Jeffries, 2010, p. 11), which is the third stage in Fairclough's (1989) three-stage model of CDA. The interest of CS is in the first and second stages (description and interpretation) of Fairclough's model (Jeffries, 2010). 
CL and CDA, according to Jeffries (2010), have stopped short of providing a coherent analytical device to expose ideological content in texts. Fairclough's (1989) analytical device is "incomplete" (Jeffries, 2010, p. 12), Fowler's (1991) is "lacking in comprehensive coverage of linguistic features" (p. 13), and Simpson's (1993) is "more satisfying methodology for analysing texts to expose ideological structures" but is also selective, the presentation of some tools is sketchy, and much of the discussion "concerns ideology in literature" (p. 14). To compensate for this "dearth of analytical device" (p. 12), Jeffries offers a ten-item list of textual functions for the investigation of ideology. The list is not altogether new; in fact, it is an accumulation of the tools used by critical linguists (Fowler, 1991; Simpson, 1993) and critical discourse analysts (Fairclough, 1989, 1992) in addition to at least one contributed by the author. Instead of presenting the tools in technical meta-linguistic language (e.g., modality, transitivity, etc.) in the tradition of CL and $\mathrm{CDA}$, Jeffries offers a list of the functions of these categories, functions that may be instantiated by more than one linguistic form. The choice of functions helps overcome "the lack of form-function mapping" as in, for example, modality (Jeffries, 2010, p. 16), and the use of the participles to name the functions (e.g., naming and describing) is a way of "dumbing-down the technical language which linguists tend to use" (p. 15).

The toolkit for the investigation of ideological control in texts provided by Jeffries (2010) include the following functions: naming and describing, representing actions/events/states, equating and contrasting, exemplifying and enumerating, prioritizing, implying and assuming, negating, hypothesizing, presenting other's speech and thoughts, representing time, space and society.

The first function provided by Jeffries (2010) is naming and describing. Jeffries argues that our way of referring to someone or something creates an ideological meaning. One of the ways of conveying an ideological effect is that we can ideologically select a noun from the alternatives provided in language. Noun phrasing by the means of modification and nominalization are two other ways. While this function concerns the use of 'nouns', 'noun phrases' or 'nominalization' to transmit ideology, the second function, representing actions/events/states, takes in the ideological consequence transfused as a result of using 'verbs'. The ideological meaning established in a text, according to this function, is related either to "what is being done (actions), what is happening (events), or what simply is (states)" (Jeffries, 2010, p. 38 [original emphasis]). This model is so much related to Halliday's system of transitivity, which has been applied by critical linguists like Simpson (1993). Equating and contrasting is Jeffries' (2010) third function that arises from the fact that there is a "possibility for words to be semantically similar or semantically opposed" (p. 52). Jefferies argues that choosing to construct a text using synonyms or antonyms carries an ideological effect. The fourth function includes the two structurally and semantically overlapping functions called exemplifying and enumerating that can be realized in, for instance, mentioning examples or listing in order to "imply incompleteness and completeness of members of a category" (p. 76). Jeffries' fifth function, named prioritizing, involves carrying focus in the clausal elements of a sentence through the exploitation of the information structure, transformation and subordination. One example of prioritizing is transforming from active to passive or vice versa, which, argues Jeffries, tends to prioritize information and indicates ideological stances towards the information provided. In implying and assuming, Jeffries' sixth function, language is employed to create assumptions and implications "to make ideologies appear to be common sense" (p. 93); that is, ideologies become naturalized. This function corresponds to the traditional terms 'implicature' and 'presupposition'. The latter has its roots in pragmatics, and Simpson (1993) makes use of it as an analytical tool to unravel ideologies in literary texts. Jeffries' seventh function is called negating, and it considers representing reality hypothetically using textual markers such as negative particles preceding verbs, negative pronouns, etc. Language power is also investigated using the eighth function, hypothesizing, which is correspondent to 'modality', a Hallidayan term employed in Simpson's (1993), where the speaker's or writer's attitude towards the world around him/her is explicitly realized in the use of modal verbs. The last two functions consider presenting others' speech and thoughts and representing time, space and society, respectively. Participants in texts, deictic terms of place, time and person are all mediators of power in texts.

CS has been applied to the analysis of political discourse with interesting findings. Alaghbary (2014), for example, explores "ideological embedding in US presidential rhetoric on aggression and conflict" with a focus on the statements by Obama on the Arab Spring uprisings in Tunisia, Egypt, Yemen, Libya, Bahrain, and Syria (p. 151). Using CS as an analytical methodology, the study uncovers "the ways in which value systems and sets of beliefs may be structured in the language of aggression and conflict, and, more specifically, the ways in which Obama's ideological attitudes and assumptions are embedded in the structure of his statements" (p. 151). The study reveals that,

[T] he Yemeni protesters are not even mentioned except in metonymic reference and the violence is morphologically nominalized to block agency; the Bahraini protesters are altogether absent and so is reference to violence; the Tunisian protesters are subordinated at low levels of structure and regime repression only logically presupposed; the Egyptian protesters are prioritized throughout the statement but violence against them is nominalized in order not to blame the government; the Libyan protesters are subordinated to the repressive practices of their government; and the Syrian protesters are qualified as peaceful while their government an agent of abhorrent violence. (p. 172)

\section{Conclusion}

The interplay of language and ideology is traceable at least the 1970s. The starting point is two seminal publications (Fowler et al., 1979; Kress \& Hodge, 1979/1993) which outline the 'manifesto' of CL, a new approach whose aim is to explore the value systems and ideological structures in different text types, such as media (Trew, 1979), university enrolment guidelines (Fowler, 1981), and swimming-pool regulations (Fowler \& Kress, 1979). For critical linguists, 
language reproduces dominant ideologies, which in turn maintain asymmetrical power relations, and, therefore, the job of the analyst is to uncover these ideologies, demystify discourse and empower discourse recipients. To realize this objective, CL adopts the descriptive apparatus of systemic functional grammar.

The thirty-one-year period spanning the years 1979-2010 has produced a plethora of approaches that investigate the language-ideology interface in news reports, political texts and other text types. Fairclough $(1989,1992)$ proposes a new direction for CL. He maintains that the "interconnectedness of language, power and ideology has been too narrowly conceived" (Simpson \& Mayr, 2010, p. 51) by critical linguists. According to Fairclough (1992), CL has focused on the text as a product (vs process) of communication and on the ideological significance of linguistic choice (grammar, semantics and vocabulary) at the expense of the larger social/economic/political ideologies that shape and are shaped by the text. Consideration of these larger contexts and of language as social practice (Fairclough \& Wodak, 1997) resulted in a proliferation of loosely grouped theories of language and ideology collectively known as Critical Discourse Analysis (or CDA). The aim of CDA researchers is to explore "the way discourse (re)produces social domination, that is, the power abuse of one group over others, and how dominated groups may discursively resist such abuse" (Wodak \& Meyer, 2009, p. 9).

The terms CL and CDA are, in fact, often used interchangeably in the literature to denote the same critical practice (Wodak \& Meyer, 2009), and the disciplines share Halliday's tripartite framework (tenor, mode and field) as the foundation of their language analysis component (Rahimi \& Riasati, 2011). CL is more text-based while some of the CDA approaches are "more sociological and political than linguistic" (Jeffries \& McIntyre, 2010, p. 193). Among these approaches are the sociocognitive approach (e.g., Dijk, 2009), the social actors approach (e.g., van Leuuwen, 2009), the dialectical-relational approach (e.g., Fairclough, 2009), and the discourse-historical approach (e.g., Reisigl \& Wodak. 2009). Although the last of these approaches is more linguistically oriented than the others, CDA integrates linguistic categories into its analyses with a different focus and intensity and does not "necessarily include a broad range of linguistic categories in each single analysis" (Wodak \& Meyer, 2009, p. 21).

The CL concern with investigating ideology using linguistic categories is brought back to the forefront by Critical Stylistics (or CS). Jeffries' (2010) exploration of "the language-power is in fact an extension of [the] research orientation initiated by Fowler et al. (1979)" (Alaghbary, 2013, p. 137). What CS adds to this existing, and rich, body of literature is a comprehensive methodology to expose insidious ideological content, and a revival of interest in the language component of critical discourse approaches to language use.

What these approaches have in common is a concern with the way processes are represented and people are positioned in discourse practices. They all assume that language does not reflect patterns of societal organization but instead produces and (re-)inforces them. The analysis uncovers the strategies of influence and manipulation employed by the discourse producers, and ultimately aims at empowering discourse recipients. What they differ in, however, is the interdiscplinarity of the approaches adopted and the rigor of linguistic analysis. CS is at one end of the spectrum, CDA is on the other, and CL falls midway between the two ends.

\section{References}

Alaghbary, G. S. (2013, July). [Review of the book Critical stylistics: The power of English, by L. Jeffries]. International Journal of Language Studies, 7(3), 137-140.

Alaghbary, G. S. (2014). The United States' reaction to the Arab Spring: A critical stylistic analysis. Journal of Language Aggression and Conflict, 2(1), 151-175.

Alazzany, M. (2014, October). Yemen-presidential political discourse during the revolution. In Y. Kalyango, Jr. and D. H. Mould (Ed.), Global jouranlism practice and new media performance (pp. 187-200). Basingstoke: Palgrave Macmillan.

Bell, A. \& Garrett, P. (Ed.). (1998). Approaches to media discourse. Oxford: Wiley-Blackwell.

Carter, R., \& Simpson, P. (1989). Language, discourse and literature: An introductory reader in discourse stylistics. London: Unwin Hyman Ltd.

Chilton, P. (2004). Analysing political discourse: Theory and practice. London: Routledge.

Eagleton, T. (1991). Ideology: An introduction. London: Verso.

Fairclough, N. (1989). Language and power. London: Longman.

Fairclough, N. (2003). Analysing discourse: Textual analysis for social research. London: Routledge.

Fairclough, N. (2008).The language of critical discourse analysis: Reply to Michael Billig. Discourse \& Society, 19, 811-819.

Fairclough, N. \& Wodak, R. (1997). Critical discourse analysis. In T. van Dijk (Ed.), Discourse as social interaction (pp. 258-84). London: Sage.

Fowler, R. (1991). Language in the news: Discourse and ideology in the press. London: Routledge.

Fowler, R., \& Kress, G. (1979). Critical linguistics. In R. Fowler, B. Hodge, G. Kress, \& T. Trew, Language and control (pp. 185-221). London: Routledge \&. Kegan Paul. 
Hall, S. (1982). The rediscovery of ideology: the return of the repressed in media studies. In M. Gurevitch, M. Curran, and J. Woollacott (Eds.), Culture, society and the media. London: Methuen.

Hodge, R., \& Kress, G. (1988). Social semiotics. Cambridge: Polity Press.

Jeffries, L. (2010). Critical stylistics: The power of English. Basingstoke: Palgrave Macmillan.

Jeffries, L., \& McIntyre, D. (2010). Stylistics. Cambridge: Cambridge University Press.

Kress, G. \& Hodge, R. (1979) Language as ideology (1st ed.). London: Routledge \&. Kegan Paul.

Kress, G. \& Hodge, R. (1993) Language as ideology (2nd ed.). London: Routledge \&. Kegan Paul.

Kuo, S. (2003, July). Language as ideology: Analyzing quotations in Taiwanese news discourse. Paper presented at the Fifteenth North American Conference on Chinese Linguistics (NACCL-15), Michigan State University, East Lansing, MI.

Lindstrand, F. (2008). Interview with Gunther Kress. Designs for learning, 1(1), 60-71.

McGregor, S. L. (2003). Critical discourse analysis-A primer. Critical science and critical discourse analysis, 15(1).

Mills, S. (1995). Feminist stylistics. London: Routledge.

Odartey-Wellington, F. (2004). The al-Qaeda sleeper cell that never was: the Canadian news media, state security apparatus and 'Operation Thread' (Doctoral dissertation, Concordia University).

Richardson, J. E. (2004). (Mis) representing Islam: The racism and rhetoric of British broadsheet newspapers (Vol. 9). John Benjamins Publishing.

Richardson, K. (1998). Signs and wonders: interpreting the economy through television. In A. Bell \& P. Garrett (Eds.), Approaches to media discourse. Oxford: Blackwell.

Scannell, P. (1998). Media language world. In A. Bell, \& P. Garrett (Ed.), Approaches to media discourse. Oxford: Blackwell.

Simpson, P. (1993). Language, ideology and point of view. London: Routledge.

Simpson, P. (2004). Stylistics: A resource book for students. London: Routledge.

Simpson, P. \& Mayr, A. (2010). Language and power. London: Routledge.

Traynor, M. (2004). Discourse analysis. Nurse researcher, 12(2), 4-6.

Trew, T. (1979). Theory and ideology at work. In R. Fowler, B. Hodge, G. Kress, \& T. Trew, Language and control (pp. 94-116). London: Routledge \&. Kegan Paul.

van Dijk, T. A. (1993, April). Principles of critical discourse analysis. Discourse \& Society, 4(2), 249-283.

van Dijk, T. A. (1998a). Ideology: A multidisciplinary approach. London: Sage.

van Dijk, T.A. (1998b). Towards a theory of context and experience models in discourse processing. In H. Van Oostendorp \& S. Goldman (Eds.), The construction of mental models during reading. Hillsdale, NJ: Erlbaum.

van Dijk, T. A. (2002). Political discourse and political cognition. Politics as Text and Talk: Analytic Approaches to Political Discourse, 203.

van Dijk, T. A. (2006, May). Discourse and manipulation. Discourse \& Society, 17(3), 359-383.

Wodak, R. (2008). Introduction: discourse studies - important concepts and terms. In R. Wodak \& M. Krzyzanowski, Qualitative discourse analysis in the Social Sciences. Palgrave, Basingstoke.

Wodak, R., \& Meyer, M. (Eds.). (2009). Methods for critical discourse analysis (2nd ed.). London: Sage. 